\section{Cold Plasma Treatment Strategies for the Control of Fusarium oxysporum f. sp. basilici in Sweet Basil}

\author{
Kathryn Homa
}

Department of Plant Biology, Rutgers University, Foran Hall, 59 Dudley Road, New Brunswick, NJ, 08901-8520; and IR-4 Project Headquarters, Rutgers University, 500 College Road East, Suite 201W, Princeton, NJ 08540

\section{William P. Barney \\ IR-4 Project Headquarters, Rutgers University, 500 College Road East, Suite $201 \mathrm{~W}$, Princeton, NJ 08540} William P. Davis, Daniel Guerrero, Mary J. Berger, and Jose L. Lopez
Department of Physics, Laboratory of Electrophysics \& Atmospheric
Plasmas, Seton Hall University, McNulty Hall, 400 South Orange Avenue,
South Orange, NJ 07079

\section{Christian A. Wyenandt}

Department of Plant Biology, Rutgers University, Rutgers Agricultural Research and Extension Center, 121 Northville Road, Bridgeton, NJ 08302

\section{James E. Simon}

New Use Agriculture and Natural Plant Products Program, Department of Plant Biology and Center for Food Agricultural EcoSystems at the New Jersey Institute of Food, Nutrition, and Health, Rutgers University, Foran Hall, 59 Dudley Road, New Brunswick, NJ 08901

Additional index words. dielectric barrier discharge, disease control, non-equilibrium atmospheric-pressure plasma, non-thermal plasma, Ocimum basilicum, plasma jet, seed treatment

\begin{abstract}
Fusarium wilt of basil (FOB), caused by Fusarium oxysporum f. sp. basilici, is an economically damaging disease of field- and greenhouse-grown sweet basil. Growers have observed a resurgence of FOB and susceptibility in FOB-resistant cultivars. Because currently available chemical, biological, and cultural control methods are costly, unsustainable, ineffective, or challenging to implement, new strategies of FOB control are needed. Cold plasma is becoming an increasingly important experimental technology in the food and agricultural industry for pathogen decontamination. To understand the effect of cold plasma treatment on FOB incidence and severity, experiments were conducted by treating FOB mycelium, inoculated sweet basil seedlings, and seeds with various experimental cold plasma treatment devices, all using helium as a feed gas. Initial results indicated that while the cold plasma jet treatment did not result in a significant reduction in mean mycelial growth rate or virulence of the pathogen, direct cold plasma jet treatments on seedlings, as well as a cold plasma dielectric barrier discharge treatment on seeds, did exhibit varying efficacies against FOB. Control of FOB appeared to be strongly dependent on the exposure time to cold plasma. These findings can aid in the standardization of a cold plasma treatment for the commercial basil seed and transplant industry.
\end{abstract}

Sweet basil (Ocimum basilicum) is grown throughout the world as an economically significant culinary herb in fields and greenhouses (Biris et al., 2004; Keinath, 1994; Reis et al., 2008; Vieira and Simon, 2000). Unfortunately, two diseases of sweet basil, basil downy mildew (BDM) caused by Peronospora belbahrii and Fusarium wilt of basil (FOB) caused by Fusarium oxysporum f. sp. basilici, greatly impact the success of this crop (Reis et al., 2008; Wyenandt et al., 2015). While both pathogens can result in yield and quality reduction, FOB infection of ponically grown basil and in field production in Plymouth County, MA (Elmer, 1995; Keinath, 1994; Wick and Haviland, 1992). Following this initial report, the pathogen was reported in several other states throughout the United States (Datnoff et al., 1997; Davis et al., 1993; Dutky and Wolkow, 1994; Holocomb and Reed, 1994; Keinath, 1993; Uchida et al., 1996). Additionally, FOB was found in many other countries, including France, Italy, Israel, southeastern Spain, Greece, Japan, South Africa, Australia, Canada, and Brazil (Biris et al., 2004; Dudai et al., 2002; Elmer et al., 1994; Gamliel et al., 1996; Grasso, 1975; Mercier and Pionnat, 1982; Moya et al., 2004; Reuveni et al., 1997; Summerell et al., 2006; Swart and van Niekerk, 2003; Taba et al., 2002; Tamietti and Matta, 1989; Trueman and Wick, 1996). More recently, growers have observed a resurgence of FOB and an increase of susceptibility in FOB-resistant cultivars (Toussaint et al., 2008; personal observation). This is especially concerning in regions where sweet basil production is an important source of revenue (Pasquali et al., 2006).

The introduction and spread of FOB throughout the world within a short timeframe resulted from the transport of contaminated commercial seed lots and transplants (Elmer et al., 1994; Gamliel et al., 1996; Martini and Gullino, 1991; Reuveni et al., 1997). Internally and externally contaminated seed from Italy was the probable introduction of FOB into the United States (Trueman and Wick, 1996; Vannacci et al., 1999). FOB-infected plants can harbor $F$. oxysporum within or on the seedcoat, which can give rise to a new generation of diseased plants and infested seed (Gamliel et al., 1996). This problem, coupled with intensive monoculture practices in the greenhouse and field, continuous re-cropping in areas with a long growing season, and the prohibition of effective eradication measures such as methyl bromide, resulted in FOB becoming an economically destructive disease throughout the world (Dudai et al., 2002; Rekah et al., 2000; Xie et al., 2015).

Because Fusarium can survive on infested seeds, effective seed treatments are paramount in providing control (Elmer et al., 1994; Gamliel et al., 1996; Keinath, 1994; Martini and Gullino, 1991). There are several methods for reducing - but not eliminating Fusarium from seed (Leslie and Summerell, 2006). Treatments with sodium hypochlorite, fungicides, hot water, heat, steam, and biocontrol agents are among the most commonly used methods (Ambrico et al., 2017; Anderegg and Guthrie, 1981; Damicone et al., 1981; Daniels, 1983; Heller and Zoller, 2010; Salama and Mishricky, 1973). Hot water treatment is the most effective seed treatment method for eliminating FOB in basil and other crops [e.g., pepper (Capsicum annuum) and tomato (Solanum lycopersicum)] (Trueman and Wick, 1996). However, this seed treatment method also has several disadvantages, including death of seed tissue and premature germination (Trueman and 
Wick, 1996). Another issue exclusively affecting the utility of basil seed treatments that entail exposure to liquids is that a mucilaginous layer surrounds the seed once it is exposed to water. This mucilaginous layer causes the wet seed to adhere tightly to surfaces and complicates efforts of effectively treating the seed, planting the seed, or maintaining it for future planting (Leslie and Summerell, 2006; Trueman and Wick, 1996).

Chemical seed treatments can significantly aid in the control of seed-borne pathogens. This treatment is preferred because it is of moderate cost and has a low environmental impact because a small amount of active ingredient is applied to the seed (Ambrico et al., 2017). However, when treating basil seed for FOB control, there are several disadvantages. There are few registered chemicals that are effective for controlling Fusarium (Ambrico et al., 2017). Treatments can result in reduction in germination and death of the seeds with no or little control of the pathogen (Ambrico et al., 2017; Chiocchetti et al., 1999; Leslie and Summerell, 2006; Trueman and Wick, 1996). Some chemicals may only partially control the pathogen (Ambrico et al., 2017; Leslie and Summerell, 2006). For example, sodium hypochlorite is widely recognized as a disinfestant for seeds and plant parts (Agarwal and Sinclair, 1997; Elmer and Stephens, 1989; Trueman and Wick, 1996). However, it cannot eliminate pathogens that are partially or completely within seed or plant tissues (Trueman and Wick, 1996). In organic farming, conventional chemical seed treatments are strictly prohibited from use (Ambrico et al., 2017).

Biological controls are also inconsistent in controlling FOB (Pasquali et al., 2006). Chitosan, an amino polysaccharide resulting from the deacetylation of chitin, did not successfully eliminate FOB and resulted in phytotoxicity, including stem browning, wilting, and the death of treated plants (Trueman

Received for publication 17 Aug. 2020. Accepted for publication 23 Oct. 2020.

Published online 17 December 2020.

Funding for this project in part was provided by the United States Department of Agriculture Specialty Crops Research Initiative project award no. 2018-03382 to Rutgers University (in concert with Cornell University, University of Florida, and University of Massachusetts), "Managing Downy Mildew and Fusarium in Basil with New Resistant Varieties, Improved Genetics, Seed Treatment, and Disease Occurrence Mapping." Partial funding was also provided by the New Use Agriculture and Natural Plant Products Program and the Rutgers Agricultural Experiment Station. Additional funding for the cold plasma generation was provided by the Laboratory of Electrophysics \& Atmospheric Plasmas (LEAP) in conjunction with the Department of Physics at Seton Hall University.

C.A.W. is the corresponding author. E-mail: wyenandt@ njaes.rutgers.edu.

This is an open access article distributed under the CC BY-NC-ND license (https://creativecommons.org/ licenses/by-nc-nd/4.0/). and Wick, 1996). The chitosan solution was also difficult to prepare for treating seed (Nabavi and Silva, 2018; Trueman and Wick, 1996). Mycostop (Verdera Oy, Finland), which is composed of mycelium and spores of a naturally occurring bacterial strain (Streptomyces griseoviridis strain K61 actinobacterium) deprives pathogenic fungi of space and nourishment by colonizing plant roots before pathogenic fungi can contact the plant (Trueman and Wick, 1996). When Mycostop was applied as a seed treatment followed by drench treatments to basil seedlings, more than half the plants displayed symptoms of wilting 5 weeks after the FOB inoculation (Trueman and Wick, 1996).

Unfortunately, little research has been conducted on FOB control in sweet basil, because it is considered a minor specialty crop. Several conventional fungicide products that have been tested in sweet basil have resulted in phytotoxicity, including a reduction in plant height or leaf weight, with no or little control of the pathogen (Ambrico et al., 2017; Chiocchetti et al., 1999; Keinath, 1994). Registered conventional compounds include cyprodonil (FRAC group 9), fludioxonil (FRAC group 12), and 1,3-dichloropropene + chloropicrin. Registered biological materials include Streptomyces lydicus WYEC 108, garlic oil, QST 713 strain of Bacillus subtilis, Bacillus amyloliquefaciens strain D747, Muscodor albus strain SA13, Pseudomonas chlororaphis strain AFS009, potassium phosphite, mono and di-potassium salts of phosphorous acid, Trichoderma harzianum Rifai strain T-22, and hydrogen peroxide + peroxyacetic acid (CDMS Label Database).

As $F$. oxysporum f. sp. basilici continues to spread and possibly genetically evolve, new options for effective control and prevention are needed (Adhikari et al., 2020; Trueman and Wick, 1996). One possible new tool is non-equilibrium atmospheric-pressure plasma, also known as cold plasma (Adhikari et al., 2020; Niedźwiedź et al., 2019). Cold plasma, also known as the fourth state of matter, is a cold, gas-like mixture of charged particles (including ions and free electrons), neutral reactive particles (including reactive oxygen and nitrogen species), ionized molecules, free radicals, and ultraviolet photons (Abbasian et al., 2017; Basaran et al., 2008; Becker et al., 2010; Bourke et al., 2018; Niedźwiedź et al., 2019; Zhu and Lopez, 2012). Plasma generation technology at atmospheric pressure is now being used in agricultural applications such as enhancing essential oil yields, enhancement of seed germination, seed decontamination, degradation of pesticides and mycotoxins, plant growth, and disease control (Abbasian et al., 2017; Adhikari et al., 2020; Bourke et al., 2018; Buonopane et al., 2016; Lee et al., 2016; Niedźwiedź et al., 2019; Selcuk et al., 2008). This technology has been shown to offer both efficient and broad-spectrum control of various bacterial and fungal pathogens in laboratory environments on plants and seeds (Adhikari et al., 2020; Ambrico et al., 2017; Bai et al., 2011; Bourke et al., 2018; Niedźwiedź et al., 2019; Sun et al., 2011).

The objectives of the following studies were to examine the effects of cold plasma treatment on $F$. oxysporum f. sp. basilici mycelium and inoculated sweet basil seedlings and seed to determine if atmospheric cold plasmas can effectively and consistently result in FOB control. These findings can aid in the standardization of a cold plasma treatment for a commercial seed and transplant treatment program

\section{Materials and Methods}

Cold plasma treatment of FOB mycelium. Full-strength $(39 \mathrm{~g} / \mathrm{L})$ potato dextrose agar (PDA) plates amended with agar (7.5 g) were prepared $1 \mathrm{~d}$ before the cold plasma treatment. When the media reached room temperature, three equidistant lines were drawn on the underside of each of three plates per treatment in each of four replicates. Using a 12.7-mm metal punch (Chang BioScience, Inc., Fremont, CA), we removed a plug from the center of a sterile, full-strength PDA plate amended with agar. A $12.7-\mathrm{mm}$ plug from a 1-month-old virulent single-spore colony of $F$. oxyporum f. sp. basilici (obtained from UMass-Amherst), growing on half-strength PDA, was inserted in the center of each sterile full--strength PDA plate amended with agar. These plates were then wrapped with parafilm (Bemis Company, Inc., Oshkosh, WI). The next day, all plates were placed into a cooler and driven to the Laboratory of Electrophysics \& Atmospheric Plasmas (LEAP) at Seton Hall University. The top surface of the mycelium plugs was treated with a non-equilibrium atmosphericpressure plasma (cold plasma) jet treatment in a circular motion at a distance of $4.5 \mathrm{~cm}$ from the bottom of the plate (Fig. 1). The cold plasma jet reactor was operated using UHP helium feed gas in atmospheric air at a rate of 5.00 standard liters per minute (SLPM), and with an applied alternating current (AC) voltage of $\approx 13 \mathrm{kV}_{\text {pk-pk }}$ at $28.8 \mathrm{kHz}$, for a total effective average electrical power usage of 15 watts (Buonopane et al., 2016; Johnson et al., 2011). Treatments consisted of a control of FOB plugs not treated with cold plasma, and FOB plugs treated with cold plasma for periods of 5,10 , or $15 \mathrm{~min}$. After all treatments were completed, plates were placed in a cooler and transported to the Rutgers SEBS greenhouse complex, where they were placed in a reach-in growth chamber (Environmental Growth Chambers, Model No. GC-15, Chagrin Falls, OH). Consistent environmental parameters were maintained $\left(24 \mathrm{~h}\right.$ of no light, $25^{\circ} \mathrm{C}$ day $/ 23^{\circ} \mathrm{C}$ night temperature and $60 \%$ relative humidity). The replicated experiment was performed on 14 Aug. 2018 and 29 Sept. 2018. Evaluations consisted of measuring the Fusarium plug diameters daily, using the lines drawn on the bottom of the plates, for a 7-d period and averaging the diameters to determine mycelial growth rate. 


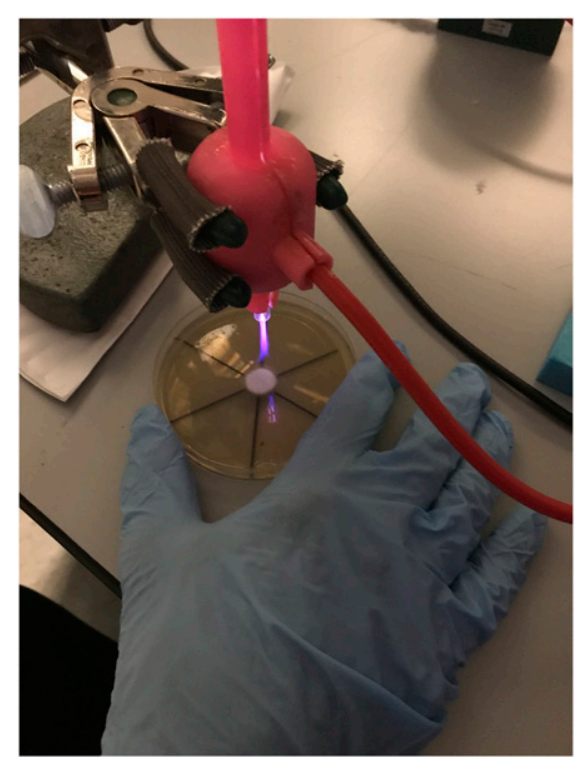

Fig. 1. Cold plasma jet treatment at a distance of 4.5 $\mathrm{cm}$ from the bottom of the plate for the treatment of Fusarium oxysporum f. sp. basilici mycelium at 5-, 10-, or 15-min time intervals at the Department of Physics, Laboratory of Electrophysics \& Atmospheric Plasmas, Seton Hall University, South Orange, NJ.

To determine if the cold plasma treatment impacted pathogen virulence, at the conclusion of the experiment, inoculum was prepared separately from each treatment by washing the control and plasma-treated plates with $10 \mathrm{~mL}$ each of deionized water and then adjusting the spore suspension to $0.785 \times 10^{6}$ conidia $/ \mathrm{mL}$. Six-leaf stage seedlings of the susceptible basil cultivar DiGenova (Johnny's Selected Seeds, Winslow, ME) were inoculated using the cut and dip method described by Reis et al. (2008). Plants were inoculated on 9 Sept. 2018 in the first experiment and on 10 Nov. 2018 in the second experiment. The inoculated plants were planted into 24-cell trays containing Redi-Earth Coir Mix Sun Gro Redi-Earth Plug and Seedling Mix Series Growing Medium (Sun Gro Horticulture, Agawam, MA). There were two control treatments: one noninoculated control treatment consisted of dipping roots in sterile deionized water, and another inoculated control treatment consisted of dipping roots in an inoculum suspension of FOB that was not treated with cold plasma. The inoculated trays were maintained in the Rutgers SEBS walk-in growth chamber (Model No. GC-96; Environmental Growth Chambers, Chagrin Falls, OH). Consistent environmental parameters were maintained $\left(28{ }^{\circ} \mathrm{C}\right.$ day temperature, $20{ }^{\circ} \mathrm{C}$ night temperature, $60 \%$ relative humidity, $450 \mu \mathrm{E} /$ $\mathrm{m}^{2} / \mathrm{s}$ radiation, 12 -h photoperiod).

Beginning $1 \mathrm{~d}$ after the inoculation, flats were gently watered once daily. Flowers were removed as necessary. Ratings of each treatment began $14 \mathrm{~d}$ after inoculation and consisted of a standard disease severity rating scale as described by Reis et al. (2004), where $1=$ no symptoms, 2 = vascular browning with no wilt symptoms, 3 = vascular browning and wilting, $4=$ severe wilting with foliar chlorosis and necrosis, and $5=$ plant death. These scores were used to develop Area Under Disease Progress Curves (AUDPC) values for comparing disease development across treatments over time. Plants were rated for disease severity once per week for a period of $35 \mathrm{~d}$ in the first experiment (final rating date 14 Oct. 2018) and $40 \mathrm{~d}$ in the second experiment (final rating date 20 Dec. 2018). At the conclusion of the experiment following the last rating, final plant heights were recorded for each plant of each treatment of each replicate.

Cold plasma treatment of sweet basil plants. On 12 Sept. 2018 (first experiment) and 17 July 2019 (second experiment), four 72-cell flats of the basil cv. DiGenova were seeded in Redi-Earth Coir Mix Sun Gro RediEarth Plug and Seedling Mix Series Growing Medium. The trays were then placed in the Rutgers SEBS greenhouse complex walk-in growth chamber and gently watered once per day for a period of 4 weeks. Consistent environmental parameters were maintained $\left(28^{\circ} \mathrm{C}\right.$ day temperature, $20{ }^{\circ} \mathrm{C}$ night temperature, $60 \%$ relative humidity, $450 \mu \mathrm{E} / \mathrm{m}^{2} / \mathrm{s}$ radiation, and at a 12 -h photoperiod).

To determine if there was a differing plant and/or pathogen response, depending on treatment, 6-leaf stage plants were either inoculated with FOB $1 \mathrm{~d}$ before or $1 \mathrm{~d}$ after the cold plasma jet treatment. Each treatment consisted of eight plants and four replicates per experiment. For treatments that were inoculated $1 \mathrm{~d}$ before the cold plasma treatment on 12 Oct. 2018 (first experiment) and 16 Aug. 2019 (second experiment), the roots of the 6-leaf stage plants were washed free of media and a 12.7-mm section of the root ends were removed with scissors. Then plants of these treatments were inoculated with a $1 \times$ $10^{6}$ conidia/mL suspension from a 1-month-old virulent single-spore colony of $F$. oxyporum $\mathrm{f}$. sp. basilici (obtained from UMass-Amherst) growing on half-strength PDA. Plants were inoculated using the cut and dip method as described by Reis et al. (2008). The inoculated plants were planted into 24-cell trays containing Redi-Earth Coir Mix Sun Gro RediEarth Plug and Seedling Mix Series Growing Medium.

For the remaining treatments, the roots of the 6-leaf stage plants were washed free of media and a $12.7-\mathrm{mm}$ section of the root ends were removed with scissors. Plants were then transplanted into 24-cell trays containing Redi-Earth Coir Mix Sun Gro Redi-Earth Plug and Seedling Mix Series Growing Medium. Plants from these treatments were inoculated $1 \mathrm{~d}$ after the cold plasma jet treatment on 14 Oct. 2018 (first experiment) or 18 Aug. 2019 (second experiment).

Each experiment also consisted of positive and negative control treatments. One non-inoculated control treatment consisted of dipping roots in sterile deionized water and not treating the plants with cold plasma. The other inoculated control treatment consisted of dipping roots in an inoculum sus- pension of $1 \times 10^{6}$ conidia $/ \mathrm{mL}$ and not treating the plants with cold plasma. After all plants from all treatments were transplanted into the 24-cell trays, they were placed back in the walk-in growth chamber, where they acclimated for a period of $\approx 12 \mathrm{~h}$.

On the day of the cold plasma jet treatment, starting with the control, all plants were removed from the 24-cell trays, washed free of media, and placed into $473-\mathrm{mL}$ plastic cups containing sterile distilled water. These cups were then tightly packed into boxes to prevent movement and driven to LEAP at Seton Hall University. All control plants remained separated from treated plants throughout the experiment. The cold plasma jet treatment was performed on 13 Oct. 2018 (first experiment) and 17 Aug. 2019 (second experiment) on bare root plants by placing the plant on a square piece of insulation foam at a distance of $4 \mathrm{~cm}$ below the jet and constantly sliding the plant back-and-forth for a set period of time of 30,60 , or $90 \mathrm{~s}$ (Fig. 2). The cold plasma jet was operated using a flow rate of 5.0 SLPM of UHP helium feed gas in air for both experiments, with an applied voltage of $13.0 \mathrm{kV}_{\mathrm{pk}-\mathrm{pk}}$ at $29.0 \mathrm{kHz}$ for the first experiment and with a $11.6 \mathrm{kV}_{\mathrm{pk}}$ pk voltage potential at $28.0 \mathrm{kHz}$ for the second experiment. A solution of $70 \%$ ethanol was used to carefully clean the surface of the square piece of insulation foam before each treatment. Immediately after each treatment was performed, plants were placed back in the plastic cups containing sterile distilled water.

After all cold plasma treatments were complete, plants were transported back to the Rutgers SEBS greenhouse complex, where they were transplanted into 24-cell trays and placed back in the walk-in growth chamber with the same environmental conditions as mentioned previously. Ratings of each treatment began 2 weeks after the inoculation and consisted of the standard disease severity rating scale as described by Reis et al. (2004). Plants were rated for disease severity once per week for a period of $35 \mathrm{~d}$ in the first experiment (17 Nov. 2018) and $40 \mathrm{~d}$ in the second experiment (26 Sept. 2019). At the conclusion of the experiment following the last rating, final plant heights were recorded for each plant of each treatment of each replicate.

Cold plasma seed treatment. The seed inoculation procedure was conducted according to Lopez-Reyes et al. (2014) using the sweet basil cv. DiGenova (Johnny's Selected Seeds). Potato dextrose broth (PDB) was prepared by mixing $24 \mathrm{~g}$ of potato agar with $1000 \mathrm{~mL}$ water. This mixture was autoclaved for $20 \mathrm{~min}$ and allowed to cool. A 5-mm diameter mycelium plug from a 1-month-old virulent single-spore colony of $F$. oxysporum f. sp. basilici (obtained from UMassAmherst) growing on half-strength PDA was added to a $250-\mathrm{mL}$ flask of PDB and placed on a shaker at medium speed for $15 \mathrm{~d}$ to obtain chlamydospores. At $15 \mathrm{~d}$, the broth was centrifuged at $5000 \mathrm{rpm}$ at $4{ }^{\circ} \mathrm{C}$ for 30 min to obtain a pellet. The pellet was 


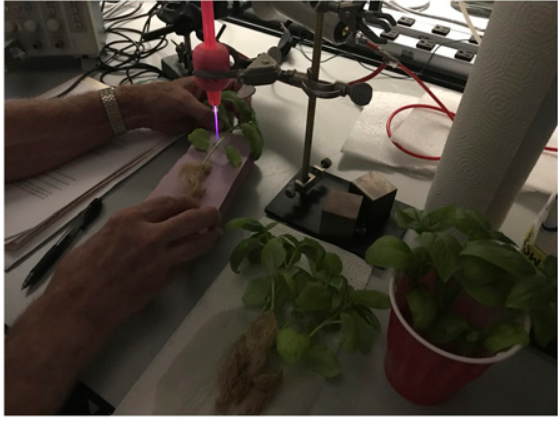

Fig. 2. Cold plasma jet treatment of six-leaf stage 'DiGenova' sweet basil seedlings at a distance of $4 \mathrm{~cm}$ below the jet at 30-, 60-, or 90-s time intervals at the Department of Physics, Laboratory of Electrophysics \& Atmospheric Plasmas, Seton Hall University, South Orange, NJ.

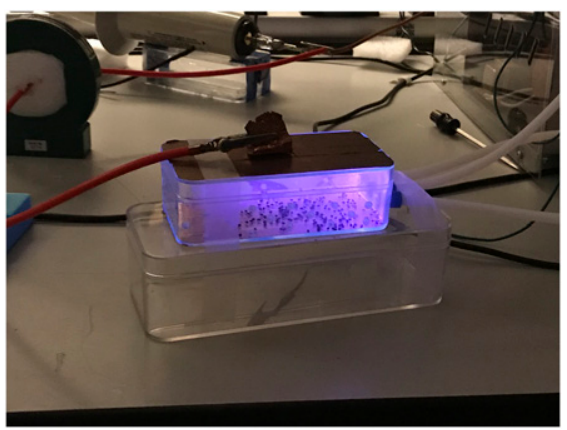

Fig. 3. Cold plasma dielectric barrier discharge seed treatment of 'DiGenova' sweet basil seed at 0.5-, 1-, 5-, 10-, and 15-min time intervals at the Department of Physics, Laboratory of Electrophysics \& Atmospheric Plasmas, Seton Hall University, South Orange, NJ

mixed with twice its weight of talc, using a spatula. The mixture was left to dry on sterile weigh paper in a sterile petri dish at $24^{\circ} \mathrm{C}$ for $15 \mathrm{~d}$ and was mixed occasionally. The concentration of the talc/chlamydospore mixture was determined by suspending a sample from the mixture in deionized water and performing a 10-fold serial dilution on a streptomycinamended PDA plate to determine number of colonies per milliliter. The calculated amount of talc/chlamydospores was mixed with $7 \mathrm{~g}$ of seed in a plastic bag to obtain a concentration of $1 \times 10^{6}$ chlamydospores/gram of seed. To obtain a batch of seed with a concentration of $1 \times 10^{3}$ chlamydospores/ gram of seed, an equal amount of untreated seed was mixed with the $1 \times 10^{6}$ chlamydospores/gram of seed. Two inoculum concentrations were used. The $1 \times 10^{6}$ chlamydospores/ gram of seed was used because this rate was used in a previous study to inoculate plants (Elmer et al., 1994). The $1 \times 10^{3}$ chlamydospores/gram of seed rate was used to imitate typical natural seed contamination rates (Lopez-Reyes et al., 2014).

A replicated experiment was performed on 0.5-g samples of seed per treatment on 20 June 2019 (first experiment) and 1 July 2019 (second experiment) at LEAP, Seton Hall
University. For both replicates, seed was inoculated at a concentration of $1 \times 10^{3}$ conidia/mL or $1 \times 10^{6}$ conidia $/ \mathrm{mL}$ on 18 June 2019 (first experiment) and 29 June 2019 (second experiment). For this experiment, a dielectric barrier discharge (DBD) containment box was specially designed for seed treatment (box dimensions were $\approx 124 \mathrm{~mm} \times$ $63 \mathrm{~mm} \times 38 \mathrm{~mm}$; made of $\approx 2-\mathrm{mm}$ thick acrylic). The box consisted of a $\approx 0.3$ cubic liter volume, with a gas residency time of $\approx 6$ $\mathrm{s}$ at 3.0 standard liter per minute. For grounding purposes, the box was set $\approx 10 \mathrm{~cm}$ above the table on foam insulation. Copper electrodes covered the outside lid and outside bottom of the box. A high-voltage lead wire was attached to the copper flap at the top of the box, while the bottom was grounded. Three 6.35-mm PTFE gas tubing inlets to flow UHP helium in atmospheric air were inserted on the left side of the box (Fig. 3).

In both replicates, inoculated seed was treated with cold plasma for designated time periods of $1,5,10$, or $15 \mathrm{~min}$. The cold plasma operating conditions for experiment one was as follows: 3.0 SLPM UHP helium gas feed, with an applied voltage potential of 11.6-11.7 $\mathrm{kV}_{\mathrm{pk}-\mathrm{pk}}$ at $28.0 \mathrm{kHz}$. The cold plasma operational parameters for experiment two was as follows: 3.0 SLPM UHP helium feed gas with an applied potential of $11.4 \mathrm{kV}$ at $27-28 \mathrm{kHz}$. After each treatment, the electrical power to the cold plasma device was turned off for a period of $5 \mathrm{~min}$ to allow the device to reach ambient temperature. The helium gas flow into atmospheric air remained on between treatments.

Following the cold plasma seed treatment, seed was collected using tweezers, placed in 59.1-mL mini cups with lids (Great Value, Bentonville, AR), and then placed into a cooler. Samples were driven back from Seton Hall University to Rutgers University for colony-forming units (cfu) tests, plating of seed, and germination tests. All tests were performed on 20 June 2019 (first experiment) and 2 July 2019 (second experiment). To determine the number of $\mathrm{cfu}$ for each seed treatment, 24 seeds per treatment were washed for serial dilutions. To confirm the incidence of FOB on seed, 12 seeds per treatment were plated on half-strength PDA per replicate, and infection was recorded for $3 \mathrm{~d}$. Seed germination index tests consisted of placing 12 seeds on two layers of filter paper moistened with sterile distilled water in sterile petri dishes for each treatment and observing the seeds for a period of $6 \mathrm{~d}$. The germination index was re-evaluated about 6 months after the initial cold plasma treatment (31 Dec. 2019) by plating and evaluating 12 seeds per treatment, in the same manner as previously described. All seed experiments consisted of four replicates per experiment

Heat-only seed treatment. We inoculated $10 \mathrm{~g}$ of 'DiGenova' seed at concentrations of $1 \times 10^{3}$ conidia $/ \mathrm{mL}$ or $1 \times 10^{6}$ conidia $/ \mathrm{mL}$ on 5 Feb. 2020 (first experiment) and 13 Feb. 2020 (second experiment) using the seed inoculation method described previously. A replicated experiment was performed on 7
Feb. 2020 (first experiment) and 14 Feb. 2020 (second experiment) in LEAP at Seton Hall University. For each treatment, seed $(\approx 0.2 \mathrm{~g}$ per sample) was placed in aluminum weigh boats, positioned on a Peltier device, and covered with another aluminum weigh boat. Heat was controlled with a Tekpower voltage controller HY152A 2AMP (Tekpower, Montclair, CA) and an EXTECH Wireless TRMS multimeter data logger (EXTECH, Nashua, $\mathrm{NH})$. In both experiments, inoculated seed was treated with heat for designated times of $1,5,10$, or $15 \mathrm{~min}$ at a range of 4.0 to $8.3 \mathrm{~V}$. The same initial and final heat values used in the cold plasma seed treatment experiments were used for the respective heat treatments.

Following the heat seed treatments, seed was placed in a cooler and driven back to Rutgers University for cfu tests, plating of seed, and germination tests as described previously. Tests were performed on 8 Feb. 2020 (first experiment) and 16 Feb. 2020 (second experiment).

Statistical analysis. Data from the replicated experiments within each series of experiments as described previously were combined. PROC MIXED analysis of the SAS System (version 9.4; SAS Institute, Cary, NC) was used for analysis of variance. Means of the cfu, number of seed with fungal colonies, percent germination, and germination index values were separated using PROC Generalized Linear Mixed Model (GLIMMIX) according to the least significant different test at $P<0.05$.

\section{Results}

Cold plasma treatment of FOB mycelium. There were no significant differences in mean mycelial growth rate between the control and the cold plasma-treated FOB mycelium at 5 , 10 , or $15 \mathrm{~min}$, suggesting that cold plasma treatment has no adverse effect on myclelial growth in culture. There was no significant difference between FOB severity or final plant height among plants inoculated with the FOB mycelium that was treated with cold plasma at 5,10 , or $15 \mathrm{~min}$ (or not treated with cold plasma), suggesting FOB treated with cold plasma before inoculation had no impact of subsequent disease severity. There was significantly less FOB severity and significantly taller plant heights in those plants not treated with cold plasma and not inoculated with FOB compared with all FOB-inoculated cold plasma-treated plants (Table 1).

Cold plasma treatment of sweet basil plants. AUDPC values for plants inoculated with FOB after cold plasma treatment were lower, but not significantly, compared with plants inoculated with FOB before cold plasma treatment. Final plant heights were significantly higher in plants inoculated with FOB after all cold plasma treatments $(30,60$, or $90 \mathrm{~s}$ ) compared with all treatments where plants were inoculated with FOB before cold plasma treatments $(30,60$, or $90 \mathrm{~s})$ (Table 2$)$. This result indicates that cold plasma treatment before inoculation with FOB resulted in significantly less stunting (e.g., taller plants) 
Table 1. Effects of cold plasma jet treatments on mycelial growth of Fusarium oxysporum f. sp. basilici (FOB), and FOB wilt severity and final plant height in FOB-susceptible 'DiGenova' sweet basil seedlings following treatment.

\begin{tabular}{lccc}
\hline Treatment & Mycelial growth rate $(\mathrm{mm} / \mathrm{d})^{\mathrm{z}}$ & FOB wilt severity & Mean final plant ht $(\mathrm{cm})$ \\
\hline FOB only; no cold plasma treatment & $8.4 \mathrm{a}^{\mathrm{x}}$ & $111 \mathrm{a}^{\mathrm{x}}$ & $9.9 \mathrm{a}^{\mathrm{x}}$ \\
FOB + cold plasma jet, 5 min & $8.9 \mathrm{a}$ & $110 \mathrm{a}$ & $10.1 \mathrm{a}$ \\
FOB + cold plasma jet, $10 \mathrm{~min}$ & $8.8 \mathrm{a}$ & $109 \mathrm{a}$ & $10.9 \mathrm{a}$ \\
FOB + cold plasma jet, 15 min & $8.9 \mathrm{a}$ & $111 \mathrm{a}$ & $10.2 \mathrm{a}$ \\
Untreated control; no cold plasma, no FOB & NA & $38 \mathrm{~b}$ & $28.6 \mathrm{~b}$ \\
\hline
\end{tabular}

${ }^{\mathrm{z}}$ Combined data from two separate experiments on mycelial growth of FOB on half-strength PDA.

${ }^{\mathrm{y}} \mathrm{FOB}$ severity rating as measured by area under disease progress curve (AUDPC) for FOB symptom development using a scale where $1=$ no symptoms, $2=$ vascular browning with no wilt symptoms, $3=$ vascular browning and wilting, $4=$ severe wilting with foliar chlorosis and necrosis, and $5=$ plant death

${ }^{x}$ PROC MIXED analysis using SAS 9.4. Means in a column are not significantly different if followed by the same lowercase letter $(P=0.05$; LSD test).

Table 2. Effects of cold plasma jet treatment of FOB-susceptible 'DiGenova' sweet basil seedlings before and after inoculation with Fusarium oxysporum f. sp. basilici (FOB) on disease development and final plant height.

\begin{tabular}{lcc}
\hline Treatment & FOB wilt severity & Mean final plant ht $\left(\mathrm{cm}^{\mathrm{z}, \mathrm{y}}\right.$ \\
\hline Control, water inoculation, no cold plasma & $40 \mathrm{a}^{\mathrm{x}, \mathrm{w}}$ & $28.9 \mathrm{a}^{\mathrm{x}, \mathrm{w}}$ \\
Control, FOB inoculation, no cold plasma & $100 \mathrm{bc}$ & $10.3 \mathrm{c}$ \\
FOB inoculation before cold plasma treatment, $30 \mathrm{~s}$ & $105 \mathrm{c}$ & $9.9 \mathrm{c}$ \\
FOB inoculation before cold plasma treatment, $60 \mathrm{~s}$ & $103 \mathrm{bc}$ & $9.1 \mathrm{c}$ \\
FOB inoculation before cold plasma treatment, $90 \mathrm{~s}$ & $103 \mathrm{bc}$ & $9.6 \mathrm{c}$ \\
Cold plasma treatment 30 s, FOB inoculation next day & $95 \mathrm{~b}$ & $16.0 \mathrm{~b}$ \\
Cold plasma treatment $60 \mathrm{~s}$, FOB inoculation next day & $96 \mathrm{bc}$ & $15.4 \mathrm{~b}$ \\
Cold plasma treatment $90 \mathrm{~s}$, FOB inoculation next day & $95 \mathrm{~b}$ & $16.7 \mathrm{~b}$ \\
\hline
\end{tabular}

${ }^{\mathrm{z}}$ Combined data from two separate experiments.

${ }^{\mathrm{y}}$ FOB severity rating as measured by area under disease progress curve (AUDPC) for FOB symptom development using a scale where $1=$ no symptoms, $2=$ vascular browning with no wilt symptoms, $3=$ vascular browning and wilting, $4=$ severe wilting with foliar chlorosis and necrosis, and $5=$ plant death

${ }^{x}$ PROC MIXED analysis using SAS 9.4. Means in a column are not significantly different if followed by the same lowercase letter $(P=0.05$; LSD test).

${ }^{\mathrm{w}}$ There was no disease in the non-inoculated control plants.

and numerically lower AUDPC values, suggesting a possible (but yet unknown) putative plant growth or defense response in sweet basil to cold plasma treatments. The effect of cold plasma on FOB growth within the plant was not studied. There was no disease in the uninoculated control.

Cold plasma seed treatment. Mean cfu, number of seed with fungal colonies, germination index, and mean final percent germination were determined. There were significantly fewer FOB cfu for cold plasmatreated seed at 5,10 , and 15 min compared with seeds inoculated with FOB and not treated with cold plasma at the $1 \times 10^{3}$ chlamydospores/gram of seed rate (Table 3 ). There were significantly fewer cfu for cold plasma-treated seed at $1,5,10$, or $15 \mathrm{~min}$ compared with seed inoculated with FOB and not treated with cold plasma at the $1 \times 10^{6}$ chlamydospores/gram of seed rate (Table 3 ). In general, there was a rate response for $\mathrm{cfu}$ from 1 to $15 \mathrm{~min}$ of cold plasma treatment at both inoculum concentrations (Table 3 ). The number of seeds with colonies was, in general, reduced as the cold plasma treatment time interval increased, with a significant reduction at the 10- and 15-min treatment times (Table 3). Cold plasma treatment of basil seed inoculated with FOB at the $1 \times 10^{3}$ chlamydospores/gramwhich is the typical natural level of Fusarium contamination in seed (Lopez-Reyes et al., 2014) - resulted in greater decontamination of seed compared with seed that was inoculated at the $1 \times 10^{6}$ chlamydospores/gram of seed (Table 3).

As a follow-up to determine if cold plasma treatment would affect long-term seed viability, percent germination and germination index were assessed on a reserved lot of seed. Seed tested 6 months after the cold plasma treatment showed a further reduction in percent germination and germination index, especially at the longer cold plasma treatment intervals of 10 and 15 min, suggesting that cold plasma treatment negatively affected germination rates after extended periods in storage (Table 4). In general, germination index and mean final percent germination were reduced at longer cold plasma treatment intervals, especially at the 10- or 15-min cold plasma treatments when the temperature ranged from $27^{\circ} \mathrm{C}$ at experiment initiation to $71{ }^{\circ} \mathrm{C}$ at experiment completion (Table 4).

Heat-only seed treatment. There was no significant reduction in cfu for heat-only treated seed at all treatment times compared with the respective inoculum level (Table 3). There was also no reduction in the number of seed with fungal colonies for all heat treatment times (Table 3). Percent germination and germination index were not significantly reduced by any of the heat treatments (Table 4). Cold plasma treatment resulted in a greater reduction in cfu and seed with fungal colonies compared with the heat treatment (Table 3). However, the cold plasma seed treatment resulted in a greater reduction in germination and germination index compared with the heat treatment, especially at the longer treatment intervals of 10 and 15 min (Table 4).

\section{Discussion}

Cold plasma technology is a new promising technology for pathogen control in the agricultural industry and has many advantages over traditional control options
(Adhikari et al., 2020). Unlike newer conventional fungicides that have a single site mode of action, cold plasma may control a wide range of plant pathogens, including those that have developed resistance to select fungicides from different FRAC groups (Adhikari et al., 2020). Cold plasma also has a minimal impact on the environment because it can be produced at atmospheric pressure and because the reactive species that are generated are unstable and shortlived (Adhikari et al., 2020; Dasan et al., 2016; Liao et al., 2018; Niedźwiedź et al., 2019).

Unfortunately, there are also several drawbacks with cold plasma technology (Adhikari et al., 2020). The largest disadvantage is incomplete deactivation of pathogens. In many cold plasma studies using various methods, there was only partial deactivation of the pathogen (Adhikari et al., 2020; Kim et al., 2017; Puligundla et al., 2018; Štěpánová et al., 2018; Xu et al., 2018). For example, in a study by Štěpánová et al. (2018), cucumber and pepper seeds treated with cold plasma using the Diffuse Coplanar Surface Barrier Discharge (DCSBD) at atmospheric pressure in ambient air resulted in the reduction of some microorganisms and pathogens on the seeds, including a complete inactivation of Cladosporium cucumerinum on cucumber seeds and a $60 \%$ to $80 \%$ reduction of Didymella licopersici spores in pepper. Additionally, viruses were still present on the seed and were not impacted by the cold plasma treatment (Štěpánová et al., 2018). Kim et al. (2017) reported the effect of corona discharge plasma jet on seed-borne microorganisms such as aerobic bacteria, molds, and yeasts in broccoli seed. After 
Table 3. Effects of cold plasma dielectric barrier discharge treatment and heat treatment of Fusarium oxysporum f. sp. basilici (FOB) on the mean CFUs, and the number of seeds with fungal colonies in 'DiGenova' sweet basil seed.

\begin{tabular}{|c|c|c|c|c|c|c|}
\hline Treatment $^{2}$ & $\begin{array}{c}\text { Plasma } \\
\text { treatment } \\
\text { mean CFUs }\end{array}$ & $\begin{array}{c}\text { Heat } \\
\text { treatment } \\
\text { mean CFUs }\end{array}$ & $\begin{array}{c}\text { Plasma number } \\
\text { of seeds with fungal } \\
\text { colonies }\end{array}$ & $\begin{array}{c}\text { Heat number } \\
\text { of seeds with } \\
\text { fungal colonies } \\
\text { fun }\end{array}$ & $\begin{array}{c}\text { Mean beginning } \\
\text { temp }\left({ }^{\circ} \mathrm{C}\right)\end{array}$ & $\begin{array}{l}\text { Mean ending } \\
\text { temp }\left({ }^{\circ} \mathrm{C}\right)\end{array}$ \\
\hline Control, no FOB, talc only, no cold plasma & $0 \mathrm{a}$ & & $0 \mathrm{a}$ & & $\frac{1}{-}$ & $\frac{1}{-}$ \\
\hline Control, no FOB, talc only, no heat & & $0 \mathrm{a}$ & & 0 & - & - \\
\hline Control, FOB inoculated, $10^{3}$, no cold plasma & $49 \mathrm{c}$ & & $12 \mathrm{f}$ & & - & - \\
\hline Control, FOB inoculated, $10^{3}$, no heat & & $54 \mathrm{bc}$ & & 12 & - & - \\
\hline Control, FOB inoculated, $10^{6}$, no cold plasma & $187 \mathrm{e}$ & & $12 \mathrm{f}$ & & - & - \\
\hline FOB inoculated, $10^{3}$, heat only, $1 \mathrm{~min}$ & & $68 \mathrm{e}$ & & 12 & 26.7 & 33.9 \\
\hline FOB inoculated, $10^{3}$, cold plasma, $5 \mathrm{~min}$ & $5 \mathrm{a}$ & & $8 \mathrm{de}$ & & 27.2 & 52.2 \\
\hline FOB inoculated, $10^{3}$, heat only, $5 \mathrm{~min}$ & & $51 \mathrm{bc}$ & & 12 & 27.2 & 51.7 \\
\hline FOB inoculated, $10^{3}$, cold plasma, $10 \mathrm{~min}$ & $1 \mathrm{a}$ & & $4 \mathrm{bc}$ & & 27.2 & 62.8 \\
\hline FOB inoculated, $10^{3}$, heat only, $10 \mathrm{~min}$ & & $39 \mathrm{~b}$ & & 12 & 26.7 & 63.3 \\
\hline FOB inoculated, $10^{3}$, cold plasma, $15 \mathrm{~min}$ & $0 \mathrm{a}$ & & $2 \mathrm{~b}$ & & 27.2 & 65.6 \\
\hline FOB inoculated, $10^{3}$, heat only, $15 \mathrm{~min}$ & & $36 \mathrm{~b}$ & & 12 & 26.7 & 69.4 \\
\hline FOB inoculated, $10^{6}$, heat only, $10 \mathrm{~min}$ & & $116 \mathrm{~d}$ & & 12 & 27.2 & 62.8 \\
\hline FOB inoculated, $10^{6}$, cold plasma, $15 \mathrm{~min}$ & $0 \mathrm{a}$ & & $4 \mathrm{bc}$ & & 22.9 & 71.1 \\
\hline FOB inoculated, $10^{6}$, heat only, $15 \mathrm{~min}$ & & $116 \mathrm{~d}$ & & 12 & 26.7 & 69.4 \\
\hline
\end{tabular}

${ }^{\mathrm{z}}$ Note that cold plasma and heat experiments were not run concurrently.

${ }^{\mathrm{y}}$ The value of 0.5 was added to each value because of the zero values and then square root transformed to satisfy the assumption of normality before PROC MIXED analysis using SAS 9.4. Means in a column are not significantly different if followed by the same lowercase letter ( $P=0.05$; LSD test). Values shown are the back transformed means.

${ }^{\mathrm{x}}$ Number of seeds with Fusarium colonies out of 12 seeds. PROC MIXED analysis using SAS 9.4. Means in a column are not significantly different if followed by the same lowercase letter $(P=0.05$; LSD test $)$.

treatment with the cold plasma jet for up to 3 min, microorganisms were reduced up to 2.3 $\log$ units, with varying levels of reduction by species. Interestingly, bacteria were inactivated much faster compared with molds and yeasts (Kim et al., 2017).

The level of pathogen deactivation depends on a number of variables: the organism being treated (i.e., seed or plant), the pathogen, the type of cold plasma system, and the degree of exposure by the cold plasma on the organism (Adhikari et al., 2020; Niedźwiedź et al., 2019). Some biological factors include the genus and species of the plant, the microenvironment of the plant-pathogen system, the species or strain of the pathogen, the structure of the cellular envelopes, and the microbial growth phase (Adhikari et al., 2020; Niedźwiedź et al., 2019).

In this study, although greater FOB control was achieved with longer cold plasma treatment times, there was not complete inactivation of the pathogen, as was shown by both the cfu results and the number of seeds with fungal colonies (Table 3). A biological explanation for lack of complete efficacy of the cold plasma treatment may be due to crevices in seeds that can protect microorganisms from cold plasma exposure (Bourke et al., 2018). In a similar study, naturally contaminated basil seed containing nine different genera of fungi were treated with surface dielectric barrier discharge (SDBD); viable conidia were identified in the micropylar region of the seed where the radicle emerges (Ambrico et al., 2017). In this study, although the mean cfu were zero after a cold plasma treatment time of $15 \mathrm{~min}$ in seed inoculated at $1 \times 10^{3}$ and $1 \times 10^{6}$ conidia $/ \mathrm{mL}$, seed from the same treatment that were directly plated on half-strength PDA revealed that some fungal colonies were still viable (Table 3). This difference in FOB presence in the seed may have been from the FOB conidia not being released from the seed crevices, and from the mucilage that was produced from the seed after the seed was being washed in deionized water for the cfu procedure (Leslie and Summerell, 2006; Trueman and Wick, 1996). These observations suggest the lack of total deactivation may also be caused by an incomplete exposure by the cold plasma on the targeted surfaces of the seeds, which may have occurred in this study.

The potential resistance of the pathogen to cold plasma treatment is another factor. There have been fewer reports of the inactivation of plant pathogenic fungi by cold plasma treatments compared with plant pathogenic bacteria (Adhikari et al., 2020). This difference was thought to be caused by differences in cytology, morphology, reproductive cycles, and growth (Bourke et al., 2018). Ambrico et al. (2017) reported that cold plasma treatment deactivated all pathogens on the seed surfaces of basil except for Alternaria spores that remained viable (Ambrico et al., 2017). The efficacy of cold plasma varies depending on the pathogen propagule, because conidia are more vulnerable to treatment compared with chlamydospores (Assaraf et al., 2002). The basil seed in this study was inoculated with FOB chla- mydospores. These resting spores are more difficult to eradicate compared with micro- or macroconidia because they contain thick cell walls that make them more resistant to adverse conditions (Sun et al., 2019). The thickness of the pathogen cell wall can strongly influence the rate of plasma etching and inactivation of microbial pathogens. This may partially explain why certain pathogens are not inactivated upon cold plasma treatment (Ambrico et al., 2017). Importantly, it has been determined that higher plasma inactivation rates are required for artificial surface inoculations using a single pathogen (e.g., FOB) compared with native microflora, which are present as multispecies communities (Bourke et al., 2018).

Does cold plasma treatment affect only the surface of the treated subject, or can it promote internal changes (Dasan et al., 2016)? Several studies have reported poor permeability of cold plasma into seed (Niedźwiedź et al., 2019). Pathogens including Fusarium can be borne on the seed surface or as a resting stage inside the seed (Trueman and Wick, 1996). To be effective, a seed treatment needs to eliminate FOB on the surface and within the seed. A small amount of FOB on the seed can result in ability of the pathogen to spread in a field, greenhouse, or hydroponic culture (Trueman and Wick, 1996).

In a similar SDBD seed treatment study in basil using humid air and high voltage, examination of the seedcoat revealed that there were chemical modifications to the seed surface, including a variation of the oxygen-to-carbon 


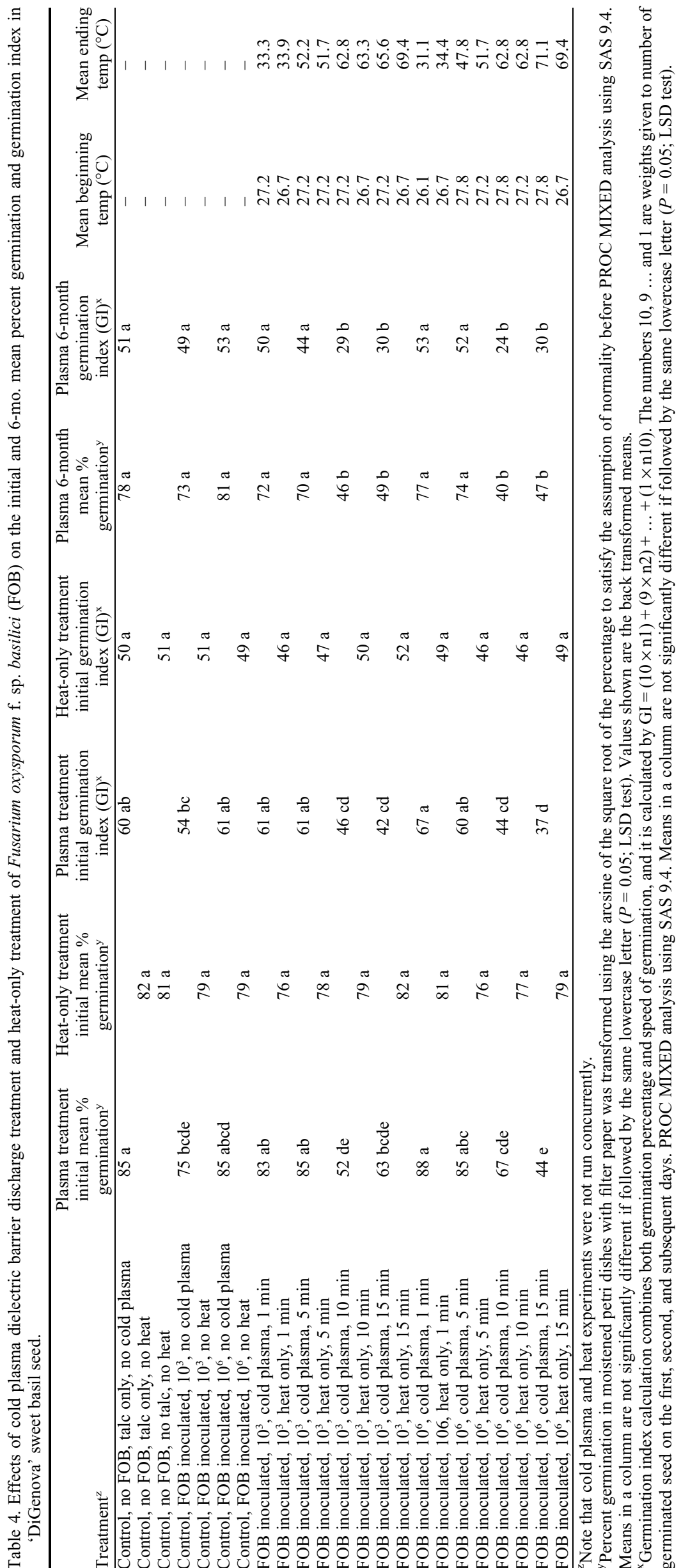

ratio in the region where the radicle emerges (Ambrico et al., 2017). From this finding, it was hypothesized that the reactive oxygen species (ROS) produced from the cold plasma treatment oxidized the external layers of seeds. The higher content of oxygen on the tegument surface in treated seed may have influenced biological processes such as growth, development, and response to biotic and abiotic stimuli. Elimination of microbial contamination by reactive oxygen and nitrogen species, and the changes in surface chemistry of the seed improves seed vigor (Ambrico et al., 2017). The mechanism of damage or death to fungal conidia on the seed was hypothesized to be DNA damage by ultraviolet radiation, lipid peroxidation, protein modulation, ROSinduced apoptosis, electrostatic disruption, and electroporation, resulting in loss of membrane integrity and leakage of intracellular components (Ambrico et al., 2017). Plasma etching caused by cold plasma jet treatment may also lead to elimination of conidia from the seed surface (Ambrico et al., 2017).

Changes to the seedcoat incurred by cold plasma treatment can accelerate germination and seedling growth (Adhikari et al., 2020; Ambrico et al., 2017; Mitra et al., 2014; Niedźwiedź et al., 2019; Sarinont et al., 2014). There are several theories for the increase in germination percentage and index. Plasma etching causes the seed's radicle micropylar regions to undergo significant morphological changes. Cold plasma treatment can detach the endosperm body from the epithelial tegument, causing cracking in the external tegument. Damage to the micropylar region is more pronounced as treatment time is increased. This may explain why emergence of the radicle is faster with increasing treatment time. There is also a loss of water that may cause the separation of internal and external coat layers from the endosperm. In treated seed, water droplets spread over a larger surface with a significantly lower contact angle. Therefore, water uptake is faster and greater in cold plasma-treated seed. This faster imbibition leads to faster seeding emergence, faster seedling growth, and a possible escape from pathogens (Ambrico et al., 2017). Other studies have concluded that faster germination may be due to microbial disinfection from the cold plasma treatment (Adhikari et al., 2020; Khamsen et al., 2016; Kordas et al., 2015; Mitra et al., 2014; Randeniya and de Groot, 2015; Štěpánová et al., 2018).

However, other studies have indicated that shorter treatment times can improve seed germination and growth, while extended treatment times can greatly reduce seed viability (Bourke et al., 2018; Štěpánová et al., 2018). In this study, increasing cold plasma treatment time led to a reduction in the germination index and the mean final percent germination in 
basil seed (Table 4). Importantly, there was a further reduction of germination index and final percent germination when seeds were tested 6 months after the cold plasma treatment (Table 4). This reduction may be due to the plasma etching causing dehydration of the seed over time and the detachment of the endosperm (Ambrico et al., 2017). Results from this study indicate that germination testing 6 months to a year after initial cold plasma treatment would be necessary when testing seed for commercial viability.

There are currently few studies that have demonstrated effective cold plasma treatment of infected leaves or roots (Adhikari et al., 2020). Compared with trying to conduct cold plasma treatment of seed, it is harder to do so with plant pathogens on roots and foliage because these plant parts can incur more damage (Seol et al., 2017; Zhang et al., 2014). Long cold plasma treatment times can result in lipid oxidation and a reduction in quality, including appearance, color, flavor, and texture in certain crop commodities (Bourke et al., 2018; Niedźwiedź et al., 2019; Puligundla et al., 2018). Damage was observed in this study in basil seedlings in the form of immediate wilting and browning of plant tissue on contact with the cold plasma jet (personal observation).

The interaction between cold plasma and the plant is complex and involves the manipulation of plant microflora, plant biochemical responses, and plant growth medium (Bourke et al., 2018). The mode of action is believed to be plasma-generated reactive species penetrating the leaf tissues through the stomata, inactivating fungal cells inside the plant tissues (Niedźwiedź et al., 2019; Zhang et al., 2014). The production of reactive species by cold plasma is thought to induce the development of defense genes via defense hormone signaling (Adhikari et al., 2020). This initiates a hypersensitive response, which in turn activates the systemic immune response (Adhikari et al., 2020; Jiang et al., 2014). In this study, a lower AUDPC value and significantly greater plant heights were observed in basil seedlings that were inoculated with FOB after the cold plasma jet treatment (Table 2). This phenomenon was also observed in a study by Jiang et al. (2014), in which cold plasma-treated tomato plants became more resistant to bacterial wilt disease after being inoculated. The leaves of the tomato plant contained an increased amount of $\mathrm{H}_{2} \mathrm{O}_{2}$ and an increase in the activities of resistant enzymes (Jiang et al., 2014). However, it is currently unknown as to whether there are long-term positive treatment effects on the plant (Bourke et al., 2018).

There are many variables in the cold plasma system that can result in differing efficacy. Cold plasmas can be generated using distinct approaches such as corona, microwave discharge, gliding arc, and dielectric barrier discharge (Niedźwiedź et al., 2019). The type of plasma source has a direct effect on the reactive components (e.g., superoxide, hydroxyl ion, hydrogen peroxide, and nitric oxide) that are generated by the cold plasma (Adhikari et al., 2020; Niedźwiedź et al., 2019; Torres et al., 2006). Other factors of importance include the temperature of the cold plasma, the electrical power input properties to the plasma reactor, treatment conditions, duration of treatment, the plasma interaction or processing, and the type of gas used to generate the plasma (Eliezer and Eliezer, 2001; Niedźwiedź et al., 2019). For example, a large-volume treatment chamber can result in reduction of the total density of plasma-reactive species and the probability of collision of these species with the crop to be treated, impacting antimicrobial efficacy (Bourke et al., 2018). Bourke et al. (2018) demonstrated that long treatment duration, and higher frequency and voltage levels promote microbial decontamination. This was demonstrated in the cold plasma seed treatment experiment in this study, where the largest decrease in FOB contamination was observed at the longest cold plasma treatment intervals of 10 and $15 \mathrm{~min}$ (Table 3 ). Treatment time is one of the most important parameters and depends on the cold plasma system design and voltage levels (Bourke et al., 2018). However, with increasing treatment time, there was an increase in temperature that negatively impacted the percent germination and germination index in this study (Table 4).

The high-temperature range of 63 to $71^{\circ} \mathrm{C}$ encountered during the long treatment times initially led to the hypothesis that the high temperatures greatly contributed to the deactivation of the FOB pathogen in this study. For this reason, a replicated heat-only treatment using a Peltier device was performed using the same temperature parameters as were encountered with the cold plasma treatment. The experiments confirmed that there was not a significant reduction in pathogen viability with increasing temperatures (Table 3). However, unlike the cold plasma treatment, none of the heat treatments resulted in a reduction in the percent germination or germination index (Table 4). This was interesting, as previous studies have indicated that temperatures above $60{ }^{\circ} \mathrm{C}$ kill most basil seed (Leslie and Summerell, 2006).

Because cold plasma can be generated using a number of gases (e.g., helium, argon, nitrogen, etc.), efficacy is also dependent on the gas source (Adhikari et al., 2020; Bourke et al., 2018; Eliezer and Eliezer, 2001). For example, wheat seed growth was inhibited when exposed to nitrogen plasma and increased when exposed to helium plasma (Bourke et al., 2018; Iranbakhsh et al., 2017). Reactive oxygen and nitrogen species (RONS) vary depending on the feeder gas, plasma device setting, and environmental conditions (Adhikari et al., 2020; Girard et al., 2016). Thus, the efficacy of microbial inactivation can differ because different RONS can exert different effects on both pathogen growth and plant growth/immunity (Basaran et al., 2008; Turkan, 2018). In this study, cold plasma was generated using he- lium in atmospheric air because this gas enables the creation of reactive species at lower power levels compared with heavier gasses such as argon. Other studies have documented partial to full elimination of Fusarium using ozone or plasma devices using air or argon as feeder gases (Abbasian et al., 2017; Filatova et al., 2013; Niyomkam, 2008; Rodrigues et al., 2015)

The use of cold plasma offers a new opportunity for disease control (Adhikari et al., 2020). However, additional studies are required to improve and standardize the application of cold plasma for decontamination and disinfection of agricultural crops (Adhikari et al., 2020). Only a few of these cold plasma technologies have been transferred to an industrial scale, such as plasmatreated water for decontaminating lettuce in Germany and decomposition of ethylene gas using DBD plasma to delay fruit ripening in Japan (Adhikari et al., 2020; Andrasch et al., 2017; Takahashi et al., 2018). Researchers are also encountering difficulty transferring cold plasma technology from the laboratory to an industrial environment. Issues include technology efficiencies, scale-up design of the technology to fit the industry, toxicology and dose, regulatory approval, validation of the cold plasma technology, and consumer acceptance (Adhikari et al., 2020; Bourke et al., 2018; Cullen et al., 2018).

Although this study demonstrated a reduction in FOB on seed and improved plant resistance to FOB, it did not completely eliminate the pathogen. A heavier gas such as argon or a direct air plasma could be tested to improve pathogen inactivation (Niedźwiedź et al., 2019). In this study, there was also an issue with high temperatures developing at longer treatment times that resulted in decreased seed germination (Table 4). A device that provides more control of heat dissipation, active area/ volume of the treatment, gas mixing, and homogeneity of the treatment would be beneficial in improving the efficacy of cold plasma seed treatment.

\section{Literature Cited}

Abbasian, E.G., M. Bayat, A.C. Nosrati, S.J. Hashemi, and M. Ghoranneviss. 2017. Study of the effect of plasma jet on Fusarium isolates with ability to produce DON toxins. World Family Medicine Journal: Incorporating the Middle East Journal of Family Medicine 99(5548):1-4, doi: 10.5742/ mewfm.2017.93126.

Adhikari, B., K. Pangomm, M. Veerana, S. Mitra, and G. Park. 2020. Plant disease control by non-thermal atmospheric-pressure plasma. Front. Plant Sci. 11:77, doi: 10.3389/fpls.2020. 00077.

Agarwal, V.K. and J.B. Sinclair. 1997. Principles of seed pathology. Vol. 1. CRC Press, Boca Raton, FL. doi: 10.3389/fpls.2020.00077.

Ambrico, P.F., M. Šimek, M. Morano, R.M.D.M. Angelini, A. Minafra, P. Trotti, M. Ambrico, V. Prukner, and F. Faretra. 2017. Reduction of microbial contamination and improvement of germination of sweet basil (Ocimum basilicum L.) seeds via surface dielectric barrier discharge. J. Phys. D Appl. Phys. 50(30):305401, doi: 10.1088/1361-6463/ aa77c8. 
Anderegg, J. and J.W. Guthrie. 1981. Seedborne Fusarium moniliforme and seedling infection in hybrid sweet corn. Phytopathology 71(11): 1196-1198, doi: 10.1094/phyto-711196.

Andrasch, M., J. Stachowiak, O. Schlüter, U. Schnabel, and J. Ehlbeck. 2017. Scale-up to pilot plant dimensions of plasma processed water generation for fresh-cut lettuce treatment. Food Packag. Shelf Life 14:40-45, doi: 10.1016/j.fpsl.2017.08.007.

Assaraf, M.P., C. Ginzburg, and J. Katan. 2002. Weakening and delayed mortality of Fusarium oxysporum by heat treatment: Flow cytometry and growth studies. Phytopathology 92(9):956963, doi: 10.1094/phyto.2002.92.9.956.

Bai, N., P. Sun, H. Zhou, H. Wu, R. Wang, F. Liu, W. Zhu, H. Lopez, J. Zhang, and J. Fang. 2011. Inactivation of Staphylococcus aureus in water by a cold, $\mathrm{He} / \mathrm{O}_{2}$ atmospheric pressure plasma microjet. Plasma Process. Polym. 8(5):424431, doi: 10.1002/ppap.201000078.

Basaran, P., N. Basaran-Akgul, and L. Oksuz. 2008. Elimination of Aspergillus parasiticus from nut surface with low pressure cold plasma (LPCP) treatment. Food Microbiol. 25(4):626-632, doi: 10.1016/j.fm.2007.12. 005.

Becker, K.H., H. Kersten, J. Hopwood, and J.L. Lopez. 2010. Microplasmas: Scientific challenges \& technological opportunities. Eur. Phys. J. D 60(3):437-439, doi: 10.1140/epjd/ e2010-00231-4.

Biris, D., D.J. Vakalounakis, and E. Klironomou. 2004. Fusarium wilt of basil in Greece: Foliar infection and cultivar evaluation for resistance. Phytoparasitica 32(2):160-166, doi: 10.1007/ bf02979782.

Bourke, P., D. Ziuzina, D. Boehm, P.J. Cullen, and K. Keener. 2018. The potential of cold plasma for safe and sustainable food production. Trends Biotechnol. 36(6):615-626, doi: 10.1016/j.tibtech.2017.11.001.

Buonopane, G.J., C. Antonacci, and J.L. Lopez. 2016. Effect of cold plasma processing on botanicals and their essential oils. Plasma Med. 6(3-4):315-324, doi: 10.1615/plasmamed.2017019125.

CDMS label database. Crop Data Management Systems, Inc., Las Vegas, NV. <http://www.cdms. net/Label-Database $>$.

Chaimovitsh, D., N. Dudai, E. Putievsky, and A. Ashri. 2006. Inheritance of resistance to Fusarium wilt in sweet basil. Plant Dis. 90(1):5860, doi: 10.1094/pd-90-0058.

Chiocchetti, A., S. Ghignone, A. Minuto, M.L. Gullino, A. Garibaldi, and Q. Migheli. 1999. Identification of Fusarium oxysporum f. sp. basilici isolated from soil, basil seed, and plants by RAPD analysis. Plant Dis. 83(6):576-581, doi: 10.1094/pdis.1999.83.6.576.

Cullen, P.J., J. Lalor, L. Scally, D. Boehm, V. Milosavljević, P. Bourke, and K. Keener. 2018. Translation of plasma technology from the lab to the food industry. Plasma Process. Polym. 15:e1700085, doi: 10.1002/ppap.201700085.

Damicone, J.P., D.R. Cooley, and W.J. Manning. 1981. Benomyl in acetone eradicates Fusarium moniliforme and $F$. oxysporum from asparagus seed. Plant Dis. 65(11):892-893, doi: 10.1094/ pd-65-892.

Daniels, B.A. 1983. Elimination of Fusarium moniliforme from corn seed. Plant Dis. 67(6):609-611, doi: 10.1094/pd-67-609.

Dasan, B.G., M. Mutlu, and I.H. Boyaci. 2016. Decontamination of Aspergillus flavus and Aspergillus parasiticus spores on hazelnuts via atmospheric pressure fluidized bed plasma reactor. Intl. J. Food Microbiol. 216:50-59, doi: 10.1016/j.ijfoodmicro.2015.09.006.

Datnoff, L.E., L.Z. Liang, and R.L. Wick. 1997. Recent outbreak of Fusarium wilt of basil in Florida. Plant Dis. 81(10):1214-1214, doi: 10.1094/pdis. 1997.81.10.1214c.

Davis, R.M., K.D. Marshall, and J. Valencia. 1993. First report of Fusarium wilt of basil in California. Plant Dis. 77(5):537, doi: 10.1094/pd77-0537c.

Dudai, N., D. Chaimovitsh, R. Reuveni, U. Ravid, O. Larkov, and E. Putievsky. 2002. Breeding of sweet basil (Ocimum basilicum) resistant to Fusarium wilt caused by Fusarium oxysporum f. sp. basilicum. J. Herbs Spices Med. Plants 9(2-3):45-51, doi: 10.1300/j044v09n02_07.

Dutky, E.M. and P. Wolkow. 1994. First report of Fusarium wilt of basil in Maryland. Plant Dis. 78:1217, doi: 10.1094/pd-78-1217b.

Eliezer, S. and Y. Eliezer. 2001. The fourth state of matter: An introduction to plasma science. IOP Publishing, UK.

Elmer, W.H. 1995. Effect of compost soil amendments and foliar micronutrient applications on Fusarium wilt of basil. Biological and Cultural Tests for Control Plant Diseases 10:129.

Elmer, W.H. and C.T. Stephens. 1989. Classification of Fusarium oxysporum f. sp. asparagi into vegetatively compatible groups. Phytopathology 79:88-93, doi: 10.1094/phyto-79-88.

Elmer, W.H., R.L. Wick, and P. Haviland. 1994. Vegetative compatibility among Fusarium oxysporum f. sp. basilicum isolates recovered from basil seed and infected plants. Plant Dis. 78(8):789-791, doi: 10.1094/pd-78-1217b.

Filatova, I., V. Azharonok, V. Lushkevich, A. Zhukovsky, G. Gadzhieva, K. Spasic, S. Zivkovic, N. Puac, S. Lazovic, G. Malovic, and Z.L. Petrovic. 2013. Plasma seeds treatment as a promising technique for seed germination improvement. In: Proceeding of the 31 st International Conference on Phenomena in Ionized Gases, p. 4-7.

Gamliel, A., T. Katan, H. Yunis, and J. Katan. 1996. Fusarium wilt and crown rot of sweet basil: Involvement of soilborne and airborne inoculum. Phytopathology 86(1):56-62, doi: 10.1094/phyto-86-56.

Garibaldi, A., M.L. Gullino, and G. Minuto. 1997. Diseases of basil and their management. Plant Dis. 81(2):124-132, doi: 10.1094/pdis.1997. 81.2.124.

Girard, P.-M., A. Arbabian, M. Fleury, G. Bauville, V. Puech, M. Dutreix, and J.S. Sousa. 2016. Synergistic effect of $\mathrm{H}_{2} \mathrm{O}_{2}$ and $\mathrm{NO}_{2}$ in cell death induced by cold atmospheric He plasma. Sci. Rep. 6:29098, doi: 10.1038/srep29098.

Grasso, S. 1975. Wilt phenomenon on basil plants caused by Fusarium oxysporum. Inf. Fitopatol. 5:5-7.

Heller, W.E. and C. Zoller. 2010. Disinfection of basil seeds is a challenge. Rech. Agron. Suisse 5:190-193.

Holocomb, G.E. and M.J. Reed. 1994. First report of Fusarium wilt of basil in Louisiana. Plant Dis. 78:1218, doi: 10.1094/pd-78-1218f.

Iranbakhsh, A., M. Ghorannevis, Z. Oraghi Ardebili, N.O. Ardebili, S.H. Tackallou, and H. Nikmaram. 2017. Non-thermal plasma modified growth and physiology in Triticum aestivum via generated signaling molecules and UV radiation. Biol. Plant. 61(4):702-708, doi: 10.1007/s10535016-0699-y.

Jiang, J., Y. Lu, J. Li, L. Li, X. He, H. Shao, and Y. Dong. 2014. Effect of seed treatment by cold plasma on the resistance of tomato to Ralstonia solanacearum (bacterial wilt). PLoS One 9(5):e97753, doi: 10.1371/journal.pone.0097753.
Johnson, V.S., W.D. Zhu, R. Wang, J.L. Re, S. Sivaram, J. Mahoney, and J.L. Lopez. 2011. A cold atmospheric-pressure helium plasma generated in flexible tubing. IEEE Trans. Plasma Sci. 39(11): 2360-2361, doi: 10.1109/tps.2011.2160737.

Keinath, A.P. 1993. Etiology of Fusarium wilt of basil in South Carolina. (Abstract A117, APS, Annual Meeting, 1993). Phytopathology 83: 1344.

Keinath, A.P. 1994. Pathogenicity and host range of Fusarium oxysporum from sweet basil and evaluation of disease control methods. Plant Dis. 78(12):1211-1215, doi: 10.1094/pd-781211.

Khamsen, N., D. Onwimol, N. Teerakawanich, S. Dechanupaprittha, W. Kanokbannakorn, K. Hongesombut, and S. Srisonphan. 2016. Rice (Oryza sativa L.) seed sterilization and germination enhancement via atmospheric hybrid nonthermal discharge plasma. ACS Appl. Mater. Interfaces 8(30):19268-19275, doi: 10.1021/ acsami.6b04555.s001.

Kim, J.W., P. Puligundla, and C. Mok. 2017. Effect of corona discharge plasma jet on surfaceborne microorganisms and sprouting of broccoli seeds. J. Sci. Food Agr. 97(1):128-134, doi: $10.1002 /$ jsfa. 7698 .

Kordas, L., W. Pusz, T. Czapka, and R. Kacprzyk. 2015. The effect of low-temperature plasma on fungus colonization of winter wheat grain and seed quality. Pol. J. Environ. Stud. 24(1):433438.

Kvartskhava, P.A. 1957. On a study of the infectious wilting (fusariosis) of eugenol basil. Rev. Appl. Mycol. 38:101-113.

Lee, K.H., H.J. Kim, K.S. Woo, C. Jo, J.K. Kim, S.H. Kim, H.Y. Park, S.K. Oh, and W.H. Kim. 2016. Evaluation of cold plasma treatments for improved microbial and physicochemical qualities of brown rice. Lebensm. Wiss. Technol. 73:442-447, doi: 10.1016/j.lwt.2016.06.055.

Leslie, J.F. and B.A. Summerell. 2006. The Fusarium Laboratory manual. 1st ed. Blackwell Publishing, Ames, IA.

Liao, X., P.J. Cullen, D. Liu, A.I. Muhammad, S. Chen, X. Ye, J. Wang, and T. Ding. 2018. Combating Staphylococcus aureus and its methicillin resistance gene (mecA) with cold plasma. Sci. Total Environ. 645:1287-1295, doi: 10.1016/j.scitotenv.2018.07.190.

Lopez-Reyes, J.G., G.G. Gilardi, A. Garibaldi, and M.L. Gullino. 2014. Efficacy of bacterial and fungal biocontrol agents as seed treatments against Fusarium oxysporum f. sp. lactucae on lettuce. J. Plant Pathol. 96(3):535-539.

Martini, P. and M.L. Gullino. 1991. Seed transmission of Fusarium oxysporum f. sp. basilicum causal agent of basil vascular wilt. (In Italian). Inf. Fitopatol. 9:59-61.

Matthews, J., M. Melendez, J. Simon, and A. Wyenandt. 2018. (Mar.). Ultra-niche crops series: Fresh-market basil. Rutgers Cooperative Extension, Fact sheet FS1279.

Mercier, S. and J.-C. Pionnat. 1982. Presence en France de la fusariose vasculaire du basilic. Seances Acad. Agric. Fr. 68:416-419.

Mitra, A., Y.F. Li, T.G. Klämpfl, T. Shimizu, J. Jeon, G.E. Morfill, and J.L. Zimmermann. 2014. Inactivation of surface-borne microorganisms and increased germination of seed specimen by cold atmospheric plasma. Food Bioprocess Technol. 7(3):645-653, doi: 10.1007/s11947-013-1126-4.

Moya, M.G., M.I. Aguilar, R. Blanco, A. Kenig, J. Gomez, and J.C. Tello. 2004. Fusarium wilt on sweet basil: Cause and sources in southeastern Spain. Phytoparasitica 32(4):395-401, doi: 10.1007/bf02979851. 
Nabavi, S.M. and A.S. Silva (eds.). 2018. Nonvitamin and nonmineral nutritional supplements. Academic Press, Cambridge, MA.

Niedźwiedź, I., A. Wasko, J. Pawlat, and M. PolakBerecka. 2019. The state of research on antimicrobial activity of cold plasma. Pol. J. Microbiol. 68(2):153-164, doi: 10.33073/pjm2019-028.

Niyomkam, N. 2008. Ozone application for controlling seed-borne pathogen and insect in rice cv. Khao Dawk Mali 105. Masters Thesis, Chiang Mai University, Thailand.

Pasquali, M., P. Piatti, M.L. Gullino, and A. Garibaldi. 2006. Development of a real time polymerase chain reaction for the detection of Fusarium oxysporum f. sp. basilici from basil seed and roots. J. Phytopathol. 154(10):632636, doi: 10.1111/j.1439-0434.2006.01160.x.

Puligundla, P., J.W. Kim, and C. Mok. 2018. Effect of atmospheric pressure plasma treatment on seed decontamination and sprouting of Pak Choi (Brassica rapa L. subsp. chinensis (L.) Hanelt). Chiang Mai J. Sci. 45(7):2679-2690.

Randeniya, L.K. and G.J. de Groot. 2015. Nonthermal plasma treatment of agricultural seeds for stimulation of germination, removal of surface contamination and other benefits: A review. Plasma Process. Polym. 12(7):608623, doi: 10.1002/ppap.201500042.

Reis, A., L.S. Boiteux, and R.F. Vieira. 2008. Search for sources of wide-spectrum resistance to Fusarium oxysporum f. sp. basilici isolates in accessions of Ocimum species. J. Gen. Plant Pathol. 74(5):375-381, doi: 10.1007/s10327008-0111-7.

Reis, A., L. de Britto Giordano, C.A. Lopes, and L.S. Boiteux. 2004. Novel sources of multiple resistance to three races of Fusarium oxysporum f. sp. lycopersici in Lycopersicon germplasm. Crop Breed. Appl. Biotechnol. 4(4):495-502, doi: 10.12702/1984-7033. v04n04a19.

Rekah, Y., D. Shtienberg, and J. Katan. 2000. Disease development following infection of tomato and basil foliage by airborne conidia of the soilborne pathogens Fusarium oxysporum $\mathrm{f}$. sp. radicis-lycopersici and $F$. oxysporum f. sp. basilici. Phytopathology 90(12):13221329, doi: 10.1094/phyto.2000.90.12.1322.

Reuveni, R., N. Dudai, E. Putievsky, W.H. Elmer, and R.L. Wick. 1997. Evaluation and identification of basil germ plasm for resistance to Fusarium oxysporum f. sp. basilicum. Plant Dis. 81(9):1077-1081, doi: 10.1094/pdis.1997.81.9. 1077.

Rodrigues, V.O., F.R. Costa, M.C. Nery, S.M. Cruz, S.G.F.D. Melo, and M.L.M.D. Carvalho. 2015. Treating sunflower seeds subjected to ozonization. J. Seed Sci. 37(3):202-210, doi: 10.1590/2317-1545v37n3148582.

Salama, A.M. and A.G. Mishricky. 1973. Seed transmission of maize wilt fungi with special reference to Fusarium moniliforme Sheld. J. Phytopathol. 77(4):356-362, doi: 10.1111/j.14390434.1973.tb04141.x.
Sarinont, T., T. Amano, S. Kitazaki, K. Koga, G. Uchida, M. Shiratani, and N. Hayashi. 2014. Growth enhancement effects of radish sprouts: Atmospheric pressure plasma irradiation vs. heat shock. In: Journal of Physics: Conference Series, 518(1):012017. IOP Publishing, Bristol, UK. doi: 10.1088/1742-6596/518/1/012017.

Selcuk, M., L. Oksuz, and P. Basaran. 2008. Decontamination of grains and legumes infected with Aspergillus spp. and Penicillum spp. by cold plasma treatment. Bioresour. Technol. 99(11):5104-5109, doi: 10.1016/j.biortech.2007. 09.076.

Seol, Y., J. Kim, S. Park, and H.Y. Change. 2017. Atmospheric pressure pulsed plasma induces cell death in photosynthetic organs via intracellularly generated ROS. Sci. Rpt. 7:589, doi: 10.1038/s41598-017-00480-6.

Štěpánová, V., P. Slavíček, L. Kelar, J. Prášil, M. Smékal, M. Stupavská, J. Jurmanová, and M. Černák. 2018. Atmospheric pressure plasma treatment of agricultural seeds of cucumber (Cucumis sativus L.) and pepper (Capsicum annuиm L.) with effect on reduction of diseases and germination improvement. Plasma Process. Polym. 15(2):1700076, doi: 10.1002/ ppap. 201700076.

Summerell, B.A., L.V. Gunn, S. Bullock, L.T. Tesoriero, and L.W. Burgess. 2006. Vascular wilt of basil in Australia. Australas. Plant Pathol. 35(1):65-67, doi: 10.1071/ap05100.

Sun, P., Y. Sun, H. Wu, W. Zhu, J.L. Lopez, W. Liu, J. Zhang, and J. Fang. 2011. Atmospheric pressure cold plasma as an antifungal therapy. Appl. Phys. Lett. 98(2):021501, doi: 10.1063/ 1.3530434.

Sun, Z.B., J. Zhang, M.H. Sun, and S.D. Li. 2019. Identification of genes related to chlamydospore formation in Clonostachys rosea 67-1. MicrobiologyOpen 8(1):e00624, doi: 10.1002/ mbo3.624.

Swart, L. and J.M. van Niekerk. 2003. First record of Fusarium oxysporum f. sp. basilici occurring on sweet basil in South Africa. Australas. Plant Pathol. 32(1):125-126, doi: 10.1071/ap02075.

Taba, S., A. Ooshiro, K. Takaesu, and T. Takushi. 2002. New wilt and crown rot disease in basil (Ocimum basilicum L.). Soil Microorganisms 56(1):31-35.

Takahashi, K., T. Motodate, K. Takaki, and S. Koide. 2018. Influence of oxygen concentration on ethylene removal using dielectric barrier discharge. Jpn. J. Appl. Phys. 57:01AG04, doi: 10.7567/jjap.57.01ag04.

Tamietti, G. and A. Matta. 1989. La tracheomicosi del basilico causata da Fusarium oxysporum $\mathrm{f}$. sp basilicum. Liguria. La Difesa delle Piante 12:213-220.

Torres, M.A., J.D. Jones, and J.L. Dangl. 2006. Reactive oxygen species signaling in response to pathogens. Plant Physiol. 141(2):373-378, doi: 10.1104/pp.106.079467.

Toussaint, J.P., M. Kraml, M. Nell, S.E. Smith, F.A. Smith, S. Steinkellner, C. Schmiderer, H. Vierheilig, and J. Novak. 2008. Effect of Glo- mus mosseae on concentrations of rosmarinic and caffeic acids and essential oil compounds in basil inoculated with Fusarium oxysporum $\mathrm{f}$. sp. basilici. Plant Pathol. 57(6):1109-1116, doi: 10.1111/j.1365-3059.2008.01895.x.

Trueman, S.L. and R.L. Wick. 1996. (August). Fusarium wilt of herbs. In: International Symposium on Medicinal and Aromatic Plants 426:365-374. doi: 10.17660/actahortic. 1996. 426.41 .

Turkan, I. 2018. ROS and RNS: Key signaling molecules in plants. J. Expt. Bot. 69:33133315, doi: 10.1093/jxb/ery198.

Uchida, J.Y., C.Y. Kadooka, and R.T. Hamasaki. 1996. First report of Fusarium wilt of basil in Hawaii and foliar disease initiation. Plant Dis. 80(1):105, doi: $10.1094 / p d-80$ $0105 b$.

Vannacci, G., C. Cristiani, M. Forti, G. Kontoudakis, and P. Gambogi. 1999. Seed transmission of Fusarium oxysporum f. sp. basilica in sweet basil. J. Plant Pathol. 81(1):47-53.

Vergovskii, V.I. 1956. Some peculiarities in the presence of fusariosis in basil. Kratk. Otchet. Nauchno Issled. Vseoyus. Inst. Maslichn. Efiromaslichn. Kult. 7:195-197.

Vieira, R.F. and J.E. Simon. 2000. Chemical characterization of basil (Ocimum basilicum L.) found in markets and used in traditional medicine in Brazil. Econ. Bot. 54(2):207-216, doi: 10.1007/bf02907824.

Wick, R.L. and P. Haviland. 1992. Occurrence of Fusarium wilt of basil in the United States. Plant Dis. 76(3):323, doi: $10.1094 / p d-76-$ 0323 b.

Wyenandt, C.A., J.E. Simon, R.M. Pyne, K. Homa, M.T. McGrath, S. Zhang, R.N. Raid, L.J. Ma, R. Wick, L. Guo, and A. Madeiras. 2015. Basil downy mildew (Peronospora belbahrii): Discoveries and challenges relative to its control. Phytopathology 105(7):885-894, doi: 10.1094/ phyto-02-15-0032-fi.

Xie, H., D. Yan, L. Mao, Q. Wang, Y. Li, C. Ouyang, M. Guo, and A. Cao. 2015. Evaluation of methyl bromide alternatives efficacy against soil-borne pathogens, nematodes and soil microbial community. PLoS One 10(2):e011798, doi: 10.1371/journal.pone. 0117980.

Xu, Z, C. Cheng, J. Shen, Y. Lan, S. Hu, W. Han, and P.K. Chu. 2018. In vitro antimicrobial effects and mechanisms of direct current airliquid discharge plasma on planktonic Staphylococcus aureus and Escherichia coli in liquids. Bioelectrochemistry 121:125-134, doi: 10.1016/ j.bioelechem.2018.01.012.

Zhang, X., D. Liu, R. Zhou, Y. Song, Y. Sun, Q. Zhang, J. Niu, H. Fan, and S.Z. Yang. 2014 Atmospheric cold plasma jet for plant disease treatment. Appl. Phys. Lett. 104(4):043702, doi: 10.1063/1.4863204.

Zhu, W.D. and J.L. Lopez. 2012. A de non-thermal atmospheric-pressure plasma microject. Plasma Sources Sci. Technol. 21(3):034018, doi: 10.1088/ 0963-0252/21/3/034018. 